\title{
Quantitative proteomics of nutrient limitation in the hydrogenotrophic methanogen Methanococcus maripaludis Qiangwei Xia ${ }^{1,2,3}$, Tiansong Wang ${ }^{2}$, Erik L Hendrickson'1, Thomas J Lie², Murray Hackett ${ }^{1}$ and John A Leigh ${ }^{* 2}$
}

Address: 'Department of Chemical Engineering, Box 355014, University of Washington, Seattle, WA 98195, USA, ${ }^{2}$ Department of Microbiology, Box 357242, University of Washington, Seattle, WA 98195, USA and ${ }^{3}$ University of Wisconsin-Madison, Department of Chemistry, Madison, WI 53706, USA

Email: Qiangwei Xia - qxia@chem.wisc.edu; Tiansong Wang - tswang@u.washington.edu; Erik L Hendrickson - elh@u.washington.edu; Thomas J Lie - tomjl@u.washington.edu; Murray Hackett - mhackett@u.washington.edu; John A Leigh* - leighj@u.washington.edu

* Corresponding author

Published: 23 July 2009

BMC Microbiology 2009, 9:149 doi:10.1/86/147|-2180-9-149
Received: 13 February 2009

Accepted: 23 July 2009

This article is available from: http://www.biomedcentral.com//47/-2/80/9//49

(c) 2009 Xia et al; licensee BioMed Central Ltd.

This is an Open Access article distributed under the terms of the Creative Commons Attribution License (http://creativecommons.org/licenses/by/2.0), which permits unrestricted use, distribution, and reproduction in any medium, provided the original work is properly cited.

\begin{abstract}
Background: Methanogenic Archaea play key metabolic roles in anaerobic ecosystems, where they use $\mathrm{H}_{2}$ and other substrates to produce methane. Methanococcus maripaludis is a model for studies of the global response to nutrient limitations.

Results: We used high-coverage quantitative proteomics to determine the response of $M$. maripaludis to growth-limiting levels of $\mathrm{H}_{2}$, nitrogen, and phosphate. Six to ten percent of the proteome changed significantly with each nutrient limitation. $\mathrm{H}_{2}$ limitation increased the abundance of a wide variety of proteins involved in methanogenesis. However, one protein involved in methanogenesis decreased: a low-affinity [Fe] hydrogenase, which may dominate over a higheraffinity mechanism when $\mathrm{H}_{2}$ is abundant. Nitrogen limitation increased known nitrogen assimilation proteins. In addition, the increased abundance of molybdate transport proteins suggested they function for nitrogen fixation. An apparent regulon governed by the euryarchaeal nitrogen regulator NrpR is discussed. Phosphate limitation increased the abundance of three different sets of proteins, suggesting that all three function in phosphate transport.

Conclusion: The global proteomic response of $M$. maripaludis to each nutrient limitation suggests a wider response than previously appreciated. The results give new insight into the function of several proteins, as well as providing information that should contribute to the formulation of a regulatory network model.
\end{abstract}

\section{Background}

Methanogenic Archaea (methanogens) occupy a distinct position in phylogeny, ecology, and physiology. Occupying much of the phylum Euryarchaeota, and widespread in anaerobic environments, these organisms produce methane as the product of energy-generating metabolism [1]. Hydrogenotrophic methanogens specialize in the use of $\mathrm{H}_{2}$ as electron donor to reduce $\mathrm{CO}_{2}$ to methane. The pathways of methanogenesis are well characterized and the proteins that catalyze steps in the pathways are known.

We are engaged in a long-term effort to understand regulatory networks in hydrogenotrophic methanogens. Our 
studies focus on Methanococcus maripaludis, a model species with tractable laboratory growth characteristics and facile genetic tools. Previous studies in M. maripaludis have begun to reveal both mechanisms of regulation and global patterns of gene expression. Many of these studies have concentrated on the effects of certain nutrient limitations. For example, at the mechanistic level, transcription of genes encoding nitrogen assimilation functions is governed by a repressor, NrpR, which is found in many Euryarchaeota as well as certain Bacteria and mediates the organism's response to nitrogen limitation [2-4]. However, a global assessment of the response to nitrogen limitation has not previously been conducted in hydrogenotrophic methanogens. At the global level, our previous studies have addressed the effects on the transcriptome of $\mathrm{H}_{2}$-limitation, phosphate-limitation, and leucine-limitation $[5,6]$. The effects of these nutrient limitations at the proteome level have not previously been studied. We have also determined the effects on the transcriptome and proteome of a mutation in a hydrogenase gene $[7,8]$.

Here we focus on the effects of certain nutrient limitations on the proteome of $M$. maripaludis. We report on the effect of limiting $\mathrm{H}_{2}$, the electron donor of hydrogenotrophic methanogenesis, and of limiting basic nutrients of biosynthesis: nitrogen and phosphate. Key aspects of our approach include the use of continuous culture for maintaining defined nutrient conditions [9], and exhaustive sampling of the proteome to obtain statistically reliable quantitative information (Xia Q, Wang T, Hendrickson $\mathrm{EL}$, Leigh JA, Hackett M, manuscript in preparation).

\section{Results and discussion Approach}

We used chemostats to grow $M$. maripaludis under three different nutrient limitations (nutrient-controlled growth) [9]. Thus, growth was limited by the supply of $\mathrm{H}_{2}$, ammonia, or phosphate to grow cultures that were $\mathrm{H}_{2}-$ limited, nitrogen-limited, or phosphate-limited, respectively. The dilution rate (and hence growth rate) was held constant, and the limiting nutrient was provided at a level that limited cell density to a similar value in each case. As before $[5,6]$, this approach allowed us to obtain a rigorous assessment of the effect of each nutrient limitation without complications arising from variations in growth rate or cell density.

Diagrams are provided that show the experimental design for sample handling and mass spectrometry analysis (Figure 1) and nutrient limitation comparisons (Figure 2). To assess the effect of each nutrient limitation, the proteome from that nutrient limitation was directly compared to the proteome from the two other nutrient limitations. For example, the effect of $\mathrm{H}_{2}$ limitation was determined from the comparison of $\mathrm{H}_{2}$-limited samples $(\mathrm{H})$ to nitrogen- limited samples $(\mathrm{N})$ and phosphate-limited samples $(\mathrm{P})$, yielding $\mathrm{H} / \mathrm{N}$ ratios and $\mathrm{H} / \mathrm{P}$ ratios respectively. Similarly, the effect of nitrogen limitation was determined from $\mathrm{N} /$ $\mathrm{H}$ and $\mathrm{N} / \mathrm{P}$ ratios, and of phosphate limitation from $\mathrm{P} / \mathrm{H}$ and $\mathrm{P} / \mathrm{N}$ ratios. This approach avoided comparison of a nutrient-limited culture to a non-nutrient-limited culture, which would introduce complications arising from variations in growth rate or cell density. Each comparison was conducted by mixing a ${ }^{14} \mathrm{~N}$-labeled (natural abundance) sample with a ${ }^{15} \mathrm{~N}$-labeled sample after digestion into tryptic fragments but prior to proteomic analysis (Figure $1)$. As a result of this approach, each nutrient limitation was assessed in a total of four comparisons, using two biological replicates with "flipped" metabolic labels for each nutrient limitation (Figure 2). Proteomics were conducted by 2-D capillary HPLC coupled with tandem mass spectrometry as before [8], with modifications as noted in Methods. Extensive proteome pre-fractionation by HPLC prior to 2-D capillary HPLC as described previously [8] and the modest size of the M. maripaludis proteome led to greater sampling depth and proteome coverage $(91 \%$ of the annotated ORFs were observed experimentally) than is typical for studies of this type [10], essentially saturating each sample in terms of protein identifications. Further repeated replicates would not have led to any significant increase in identifications at the protein level, although a few additional peptides might potentially have been matched with the database. The average number of unique peptide sequences assigned to each detected protein-encoding ORF was 10 . The average number of redundant heavy/light and light/heavy peptide pairs recovered for each detected ORF in each comparison of two nutrient limitation states, for purposes of abundance ratio generation, was 198. (Here the term "redundant" refers to measurements that include repeated sampling of the same peptide pair where each observed pair is an estimator of the relative change in protein abundance as in our previous work $[8,10]$.) However, such statistical power is a mixed blessing in that one must then distinguish between real regulatory trends and minor random changes in the system. With so many redundant measurements, it becomes possible to detect very small abundance changes, of magnitude $10 \%$ or less, that may or may not have biological meaning [10]. Biological relevance was inferred in part by looking at the consistency of change observed across nutrient limitation comparisons and biological replicates (isotopic flips), as well as the magnitude of the $q$-values for each abundance ratio and the criteria given below.

All ratios and statistical values are provided in Additional file 1. Protein abundance was considered to be affected by a particular nutrient limitation only if a significant difference $\left(\log _{2}\right.$ ratio $\neq 0, q$-value $\left.\leq 0.01\right)$ was seen in all four comparisons described above, except in a few cases where manual inspection of the data suggested that one of the 

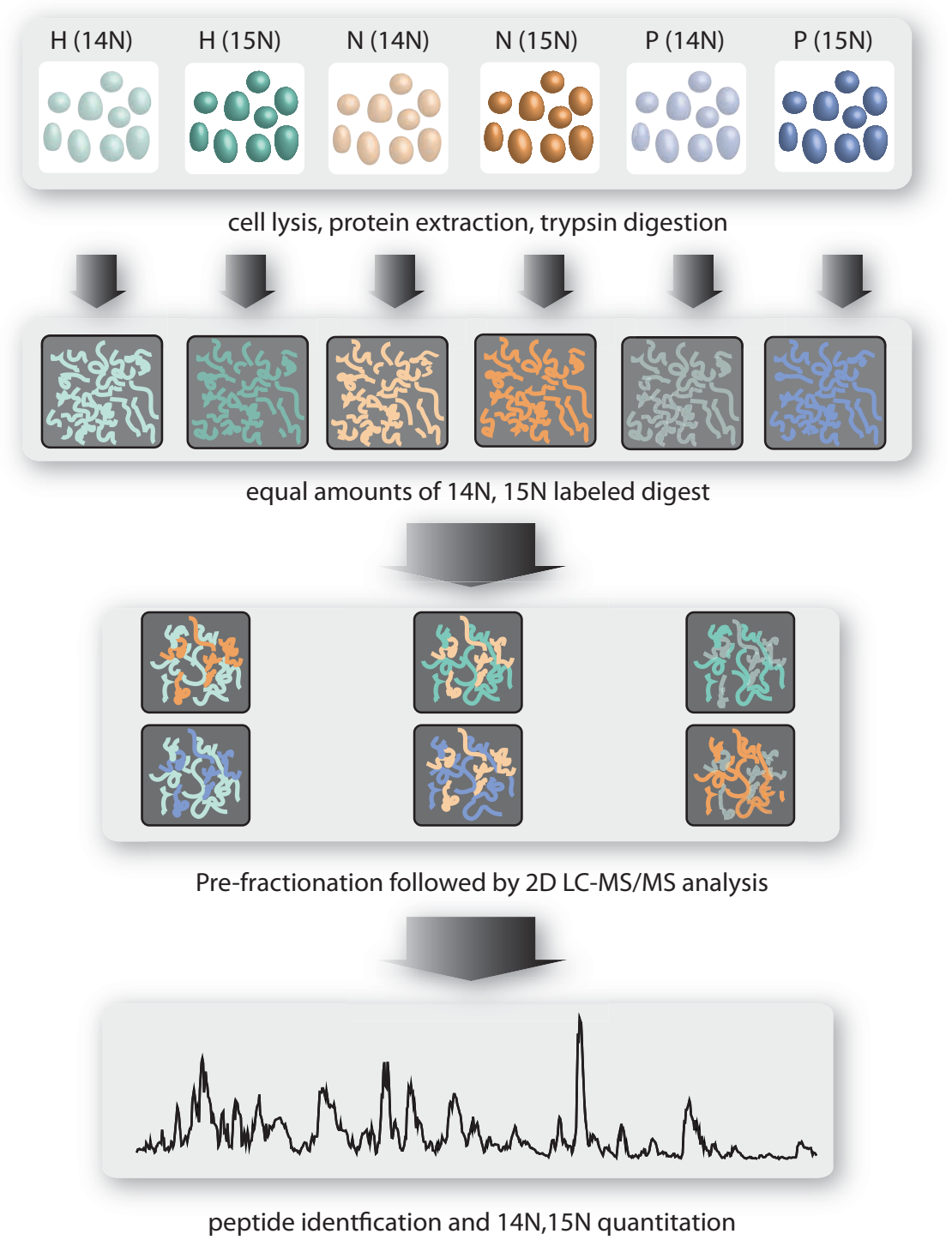

\section{Figure I}

Experimental design, sample handling and raw data acquisition. The bottom panel is a representation of a single reversed-phase elution during the final stage of the 2-D HPLC tandem MS analysis, total signal (reconstructed ion current, $y$ axis) versus time (x-axis), of $M$. maripaludis proteolytic fragments.

four determinations was an outlier, in which case it was disregarded. qRT-PCR was used to assess mRNA abundance ratios for selected ORFs. These measurements confirmed the proteomic trends in each case tested, and also contributed data supporting the concept that proteomic abundance ratios generated using shotgun methods are compressed $[8,10]$, that is, they tend to underestimate the magnitude of the ratios, especially for highly expressed proteins or high ratios as shown in Tables 1 and 2 and discussed below. The observed compression is consistent with the dynamic range limitations associated with both shotgun proteomics $\left(\sim 10^{2}\right.$ to $\left.\sim 10^{3}\right)$ and mRNA microarray analysis, relative to qRT-PCR [10].

\section{$\boldsymbol{H}_{2}$ limitation}

The abundance of 141 proteins ( $8 \%$ of the 1722 annotated ORFs) was significantly affected by $\mathrm{H}_{2}$-limitation; 59 had increased abundance and 82 decreased. $\mathrm{H} / \mathrm{N}$ and $\mathrm{H} /$ $P$ ratios and their averages are shown in Additional file 2. The functional category of proteins that most frequently increased was methanogenesis (Table 1). In a previous study at the transcriptome level [5], only a subset of the mRNAs encoding the proteins of methanogenesis was seen to increase significantly; these included the $\mathrm{F}_{420^{-}}$ reducing hydrogenase ( $f r u$ ), methylenetetrahydromethanopterin reductase (mer), and methylenetetrahydromethanopterin dehydrogenase $(m t d)$, all encoding enzymes 


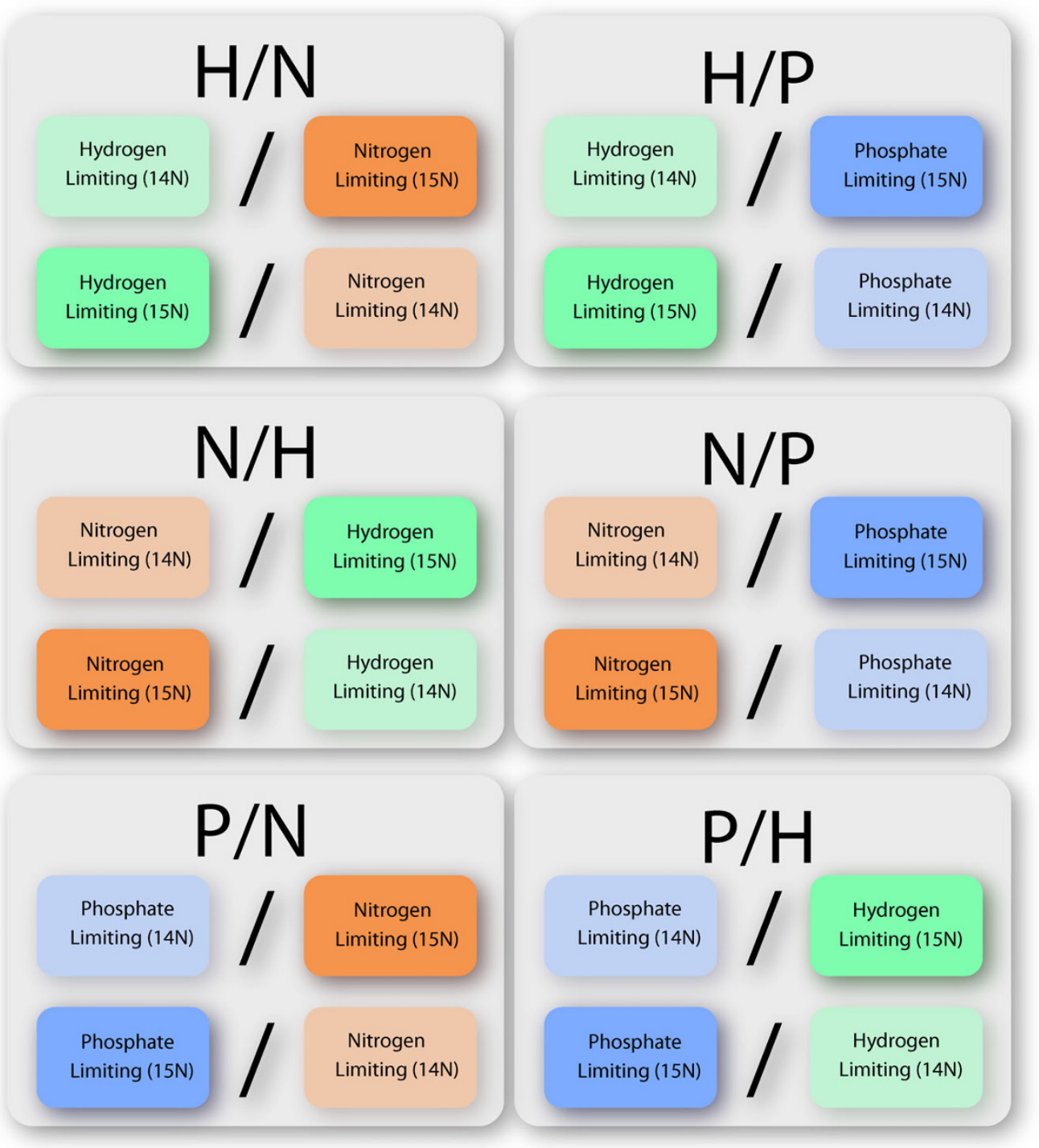

\section{Figure 2}

Experimental design, computational. The effect of each nutrient limitation was assessed by comparing its proteome to that from the two other nutrient limitations, thus providing two control conditions for each condition under study, green, $\mathrm{H}_{2}$ limitation; orange, nitrogen limitation; blue, phosphate limitation; light colors, light isotope ( ${ }^{14 \mathrm{~N}}$ ); dark colors, heavy isotope $(15 N)$.

that reduce or oxidize coenzyme $\mathrm{F}_{420}$. In contrast, in the current study of the proteome, many enzymes in methanogenesis that do not metabolize $\mathrm{F}_{420}$ increased as well. Another difference between the results of the previous transcriptome study and the current proteomics study was in the magnitude of the increase for the $\mathrm{F}_{420}$-metabolizing enzymes; whereas these mRNAs were previously seen to increase markedly (4-22 fold), the magnitude of change in protein abundance in the current study was at most 2.5fold. The lower magnitude of change in the current study held at the mRNA level, since qRT-PCR of $m t d$ revealed an average $\log _{2}$ ratio of only 0.89 (1.9-fold), compared to 4.3 (19.7-fold) in the previous study.
There are several possible reasons why the current study reflects more widespread but less marked changes than the earlier study of the transcriptome. First, our measurement of abundance changes and the significance of those changes have different limitations for the transcriptome and the proteome. Much of the proteome was very heavily sampled in this study, so statistically significant differences are more easily discerned as discussed above. Second, even if the transcriptome study were statistically robust, effects on protein abundance could occur at a post-mRNA level. It should be noted that these first two explanations may apply to the non- $\mathrm{F}_{420}-$ metabolizing enzymes, but for the $\mathrm{F}_{420}$-metabolizing enzymes it is 
Table I: Selected proteins with altered abundance under $\mathrm{H}_{2}$ limitation.

\begin{tabular}{|c|c|c|}
\hline ORF \# & Function & Average $\log _{2}$ ratio \\
\hline & Methanogenesis & \\
\hline MMP0820 & FrcA, coenzyme $\mathrm{F}_{420}$-reducing hydrogenase & $1.30 \pm 0.56$ \\
\hline MMPI382 & FruA, coenzyme $\mathrm{F}_{420}$-reducing hydrogenase & $0.77 \pm 0.16$ \\
\hline MMPI384 & FruG, coenzyme $\mathrm{F}_{420}$-reducing hydrogenase & 0.88 \\
\hline MMPI 385 & FruB, coenzyme $\mathrm{F}_{420}$-reducing hydrogenase & 0.90 \\
\hline MMPI460 & EhaM, energy-conserving hydrogenase $\mathrm{A}$ & $0.56 \pm 0.08$ \\
\hline MMPI463 & EhaP, energy-conserving hydrogenase A polyferredoxin subunit & $0.64 \pm 0.27$ \\
\hline MMP0058 & Mer, methylenetetrahydromethanopterin reductase & 0.58 \\
\hline MMPI245 & FwdF, formylmethanofuran dehydrogenase & 0.20 \\
\hline MMPI 247 & FwdD, formylmethanofuran dehydrogenase & 0.23 \\
\hline MMPI 248 & FwdA, formylmethanofuran dehydrogenase & 0.27 \\
\hline MMPI249 & FwdC, formylmethanofuran dehydrogenase & $0.28 \pm 0.07$ \\
\hline MMPI697 & HdrA, heterodisulfide reductase & $0.35 \pm 0.18$ \\
\hline MMPI696 & VhuD, $\mathrm{F}_{420}$ non-reducing hydrogenase & $0.35 \pm 0.11$ \\
\hline MMPI695 & VhuG, $\mathrm{F}_{420}$ non-reducing hydrogenase & 0.34 \\
\hline MMPI694 & VhuA, $\mathrm{F}_{420}$ non-reducing hydrogenase & 0.29 \\
\hline MMP0372 & Mtd, $\mathrm{F}_{420^{-}}$dependent methylenetetrahydromethanopterin dehydrogenase & $0.35 \pm 0.10(0.89)^{\mathrm{b}}$ \\
\hline MMPI054 & $\mathrm{HdrC} 2$, heterodisulfide reductase & 0.33 \\
\hline MMPI053 & $\mathrm{HdrB2}$, heterodisulfide reductase & $0.33 \pm 0.11$ \\
\hline MMPI563 & MtrB, methyltransferase & $0.27 \pm 0.16$ \\
\hline MMPI564 & MtrA, methyltransferase & 0.09 \\
\hline MMPOI 27 & $\mathrm{Hmd}, \mathrm{H}_{2}$-dependent methylenetetrahydromethanopterin dehydrogenase & $-2.08(-3.57)^{\mathrm{b}}$ \\
\hline MMPOI 25 & Hypothetical protein & -1.19 \\
\hline MMP0875 & S-layer protein & -1.25 \\
\hline MMPII76 & Putative iron transporter subunit & -0.83 \\
\hline MMPI206 & GlnA, glutamine synthetase & -0.35 \\
\hline
\end{tabular}

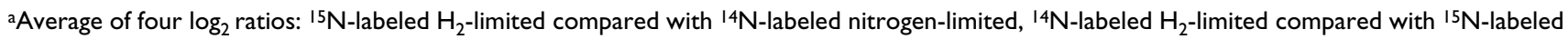
nitrogen-limited, ${ }^{15} \mathrm{~N}$-labeled $\mathrm{H}_{2}$-limited compared with ${ }^{14} \mathrm{~N}$-labeled phosphate-limited, and ${ }^{14} \mathrm{~N}$-labeled $\mathrm{H}_{2}$-limited compared with ${ }^{15} \mathrm{~N}$-labeled phosphate limited. Standard deviations are given. Where protein abundance was affected by a second nutrient limitation (other than $\mathrm{H}_{2}$ ), the average is from two ratios only, each $\mathrm{H}_{2}$-limited compared with the non-affecting nutrient limitation.

bValues in parentheses represent measurements of mRNA by qRT-PCR.

insufficient, based on our qRT-PCR measurements of $m t d$. Third, a caveat to the comparison of the two studies is that growth conditions were different, since the previous study was conducted with a richer medium and at a higher growth rate than the current study. Finally, it should be noted that the strain used in the current study differs from the strain used previously. Mm900, the strain used in the current study, contains a deletion of the $h p t$ gene encoding hypoxanthine phosphoribosyltransferase [11], while S52, the strain used in the previous study, is a leucine auxotroph containing a deletion of the leuA gene [9]. While the known differences lie outside of hydrogen metabolism or methanogenesis, it is conceivable that there were unknown consequences for methanogenesis. In any case, the results of the current study show that effects of $\mathrm{H}_{2}$-limitation occur widely for proteins of methanogenesis. The overall increase in methanogenic proteins with $\mathrm{H}_{2}$ limitation likely reflects a regulatory response that maintains flux through the methanogenic pathway when the electron donating substrate is limiting.

One protein decreased strikingly with $\mathrm{H}_{2}$-limitation, the $\mathrm{H}_{2}$-dependent methylenetetrahydromethanopterin dehy- drogenase, Hmd (Table 1). The previous study of the transcriptome [5] indicated an increase in hmd mRNA with faster growth, but no change with $\mathrm{H}_{2}$-limitation. The discrepancy could be explained by any of the factors discussed above. In any case, the results indicate that Hmd has a decreased role under $\mathrm{H}_{2}$-limitation. In hydrogenotrophic methanogens, Hmd catalyses the reduction of methenyltetrahydromethanopterin to methylenetetrahydromethanopterin, using $\mathrm{H}_{2}$ directly as electron donor. As such, Hmd provides an alternative to $\mathrm{F}_{420}$-reducing hydrogenase (Fru or Frc in M. maripaludis) and $\mathrm{F}_{420}$-dependent methylenetetrahydromethanopterin dehydrogenase (Mtd) working together: Fru or Frc reduces $\mathrm{F}_{420}$ using $\mathrm{H}_{2}$, and Mtd reduces methenyltetrahydromethanopterin to methylenetetrahydromethanopterin using reduced $\mathrm{F}_{420}$. Hmd is an unusual [Fe] hydrogenase that has a lower affinity for $\mathrm{H}_{2}$ than the $\mathrm{F}_{420}$-reducing hydrogenases $[12,13]$, and could be preferred when $\mathrm{H}_{2}$ is in excess, while Fru or Frc with Mtd could be preferred when $\mathrm{H}_{2}$ is limiting. Other proteins that decreased were a hypothetical protein (encoded in a putative operon with Hmd), a putative iron transporter subunit, glutamine synthetase, and an S-layer protein (MMP0875). An additional S-layer 
Table 2: Selected proteins with altered abundance under nitrogen limitation.

\begin{tabular}{|c|c|c|}
\hline ORF \# & Function & Average $\log _{2}$ ratio $^{a}$ \\
\hline & Nitrogen fixation & \\
\hline MMP0853 & $\mathrm{NifH}$, nitrogenase reductase & $2.29 \pm 0.16$ \\
\hline MMP0854 & $\mathrm{Nifl}_{1}$ & $1.68 \pm 0.57$ \\
\hline MMP0855 & $\mathrm{Nifl}_{2}$ & $2.10 \pm 0.23$ \\
\hline MMP0856 & NifD, nitrogenase & $2.45 \pm 0.15$ \\
\hline MMP0857 & NifK, nitrogenase & $2.03 \pm 0.22(7.09)^{b}$ \\
\hline MMP0858 & NifE & $1.85 \pm 0.42$ \\
\hline MMP0859 & NifN & $1.65 \pm 0.30$ \\
\hline MMP0860 & NifX & $3.13 \pm 0.60$ \\
\hline \multirow[t]{2}{*}{ MMP0446 } & NifX-NifB superfamily & $1.05 \pm 0.40$ \\
\hline & Ammonia transport and regulation & \\
\hline MMP0064 & $\mathrm{GlnK}_{\mathrm{I}}$ & 1.30 \\
\hline MMP0065 & $\mathrm{AmtB}_{\mathrm{I}}$ & $2.81 \pm 0.31$ \\
\hline MMP0066 & $\mathrm{G} \ln \mathrm{B}$ & $0.45 \pm 0.41$ \\
\hline \multirow[t]{2}{*}{ MMP0067 } & $\mathrm{GlnK}_{2}$ & $1.59 \pm 0.48$ \\
\hline & Ammonia assimilation & \\
\hline \multirow[t]{2}{*}{ MMPI 206} & GlnA, glutamine synthetase & 1.23 \\
\hline & Molybdate transport & \\
\hline MMP0205 & ModA, molybdate binding protein & $2.11 \pm 0.47$ \\
\hline MMP0507 & ModA, molybdate binding protein & $2.24 \pm 0.50$ \\
\hline MMP05I6 & ModD, molybdate transporter subunit & $0.73 \pm 0.23$ \\
\hline
\end{tabular}

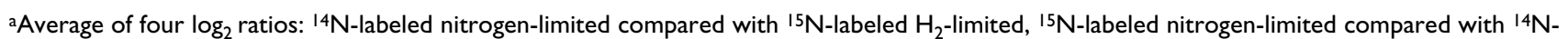
labeled $\mathrm{H}_{2}$-limited, ${ }^{15} \mathrm{~N}$-labeled nitrogen-limited compared with ${ }^{14} \mathrm{~N}$-labeled phosphate-limited, and ${ }^{14} \mathrm{~N}$-labeled nitrogen-limited compared with ${ }^{15} \mathrm{~N}$-labeled phosphate limited. Standard deviations are given. Where protein abundance was affected by a second nutrient limitation, average is from two ratios only, each nitrogen-limited compared with the non-affecting nutrient limitation.

bValue in parentheses represents measurements of mRNA by qRT-PCR.

protein (MMP0383) was not significantly affected by any nutrient limitation.

\section{Nitrogen limitation}

The abundance of 106 proteins was significantly affected by nitrogen limitation; 79 had increased abundance and 27 decreased. N/H and N/P ratios and their averages are shown in Additional file 3. Of the 79 proteins with increased abundance, 13 have known functions in nitrogen assimilation (Table 2). These are the nitrogen fixation (Nif) proteins, glutamine synthetase (GlnA) which assimilates ammonia, ammonia transporters (Amt), and nitrogen sensor/regulators (GlnK).

Since the Nif proteins showed a consistent and relatively marked increase in abundance, the mRNA encoding one (nifK) was selected for qRT-PCR to determine whether the effect occurred with similar magnitude at the transcriptome level. The magnitude was much greater, with an average $\log _{2}$ ratio of 7.09 (136-fold) for the mRNA compared to 2.03 (4.1-fold) for the protein. Previous measurements of nif transcription using lacZ fusions also showed a greater magnitude of regulation (5-100 fold, $[14,15])$. The results suggest that for proteins that are present at high levels under derepressed conditions, the proteomic ratios may be compressed as noted above. In nitrogen-fixing organisms in general, Nif proteins are present at high levels under nitrogen-fixing conditions when fixed nitrogen species are not available or are present at limiting amounts, but are absent when available fixed nitrogen is in excess.

Other proteins were not previously predicted to function in nitrogen assimilation, yet increased in abundance with nitrogen limitation (Table 2). Three such proteins were predicted subunits of three molybdate transporters, and their response to nitrogen limitation suggests that they function to transport molybdate for conversion into the iron-molybdenum cofactor (FeMoCo) of nitrogenase. A protein belonging to the NifB-NifX family of FeMoCo synthesis proteins also increased.

Surprisingly, several proteins that play central roles in carbon assimilation also increased: subunits of pyruvate oxidoreductase and oxoisovalerate oxidoreductase, as well as acetyl-CoA synthetase (AMP-forming). In hydrogenotrophic methanogens, pyruvate oxidoreductase and oxoisovalerate oxidoreductase each reductively assimilates $\mathrm{CO}_{2}$. In addition, ATPase increased moderately (Additional file 3). Proteins that decreased with nitrogen limitation included flagellins, chemotaxis proteins, certain proteins of methanogenesis, and HmdII, a homolog of the $\mathrm{H}_{2}$-dependent methylenetetrahydromethanopterin 
dehydrogenase Hmd. HmdII is not known to have the catalytic activity of Hmd and its function is unknown.

A known transcriptional nitrogen regulator, NrpR, binds to operators with consensus sequence GGAAN $_{6}$ TTCC $[3,4]$. The intergenic regions in $M$. maripaludis that contain this sequence are upstream of the following genes: the nif operon, the $g \ln K-a m t B$ operon, $g \ln A$, two of the three molybdate transporter operons (MMP0205-0207 and MMP0504-0507), and a gene encoding a $\mathrm{Na}^{+}$-alanine symporter (MMP1511). (The $\mathrm{Na}^{+}$-alanine symporter may function in nitrogen assimilation since alanine is a nitrogen source for M. maripaludis, [11].) Data presented above suggest for all of these genes except the $\mathrm{Na}^{+}$-alanine symporter that nitrogen regulation indeed occurs. Furthermore, NrpR-dependent regulation of nif and $g \ln A$ has been documented previously $[3,4,16]$. Since the proteomics data for the $\mathrm{Na}^{+}$-alanine symporter was inconclusive, we tested for nitrogen regulation by growing batch cultures on the preferred, intermediate, and non-preferred nitrogen sources ammonia, $\mathrm{L}$-alanine, and $\mathrm{N}_{2}$, using a promoter-lac $Z$ fusion. $\beta$-galactosidase activities were 1060, 2147, and 3122 (standard deviations 21, 193, and 178) respectively, indicating that the gene for the $\mathrm{Na}^{+}$alanine symporter is also regulated by nitrogen. Hence, the following genes are likely regulated directly by NrpR: nif and $g \ln A$ as documented previously, the $g \ln K-a m t B$ operon, the two molybdate transporter operons MMP0205-0207 and MMP0504-0507, and the $\mathrm{Na}^{+}$ alanine symporter gene. The remaining proteins affected by nitrogen limitation, including the NifB-NifX homolog and the third molybdate transporter MMP0514-0516, may respond indirectly to NrpR or may be influenced by different mechanisms.

\section{Phosphate limitation}

The abundance of 163 proteins was significantly affected by phosphate limitation; 80 proteins increased and 83 decreased. $\mathrm{P} / \mathrm{H}$ and $\mathrm{P} / \mathrm{N}$ ratios and their averages are shown in Additional file 4. The proteins that increased the most markedly were those of a phosphate $\mathrm{ABC}$ transporter (Table 3). Homologous phosphate transporters are present in a wide variety of Bacteria, where they are similarly affected by phosphate limitation [17]. Also affected were a homolog of a phosphate transport regulator (PhoU) encoded adjacent to another set of ABC transporter subunits, and a putative $\mathrm{Na}^{+}$-phosphate cotransporter. All of these were also affected by phosphate limitation at the mRNA level, with the phosphate $\mathrm{ABC}$ transporter (MMP1095-1099) the most markedly regulated [6]. These results suggest that $M$. maripaludis has three different phosphate transporters, all of which are regulated by phosphate conditions. Proteins that decreased with phosphate limitation included the $\mathrm{CO}_{2}$ assimilating carbon monoxide dehydrogenase/acetylCoA
Table 3: Selected proteins with altered abundance under phosphate limitation.

\begin{tabular}{lll}
\hline ORF \# & Function & Average $\log _{2}$ ratio $^{a}$ \\
\hline & Phosphate transport & \\
MMPI095 & Phosphate binding protein & $2.15 \pm 0.30$ \\
MMPI096 & Phosphate transporter subunit & $2.12 \pm 0.47$ \\
MMPI098 & ATP binding protein & $2.16 \pm 0.18$ \\
MMPI099 & PhoU, regulator & $1.16 \pm 0.29$ \\
MMPI199 & $\mathrm{PhoU}$ homolog & $1.26 \pm 0.16$ \\
MMP0666 & $\mathrm{Na}^{+} / \mathrm{P}_{\mathrm{i}}$ cotransporter & $1.16 \pm 0.32$ \\
\hline
\end{tabular}

aAverage of four $\log _{2}$ ratios: ${ }^{14} \mathrm{~N}$-labeled phosphate-limited compared with ${ }^{15} \mathrm{~N}$-labeled $\mathrm{H}_{2}$-limited, ${ }^{15} \mathrm{~N}$-labeled phosphate-limited compared with ${ }^{14} \mathrm{~N}$-labeled $\mathrm{H}_{2}$-limited, ${ }^{14} \mathrm{~N}$-labeled phosphate-limited compared with ${ }^{15} \mathrm{~N}$-labeled nitrogen-limited, and ${ }^{15} \mathrm{~N}$-labeled phosphate-limited compared with ${ }^{14} \mathrm{~N}$-labeled nitrogen limited. Standard deviations are given.

synthase, acetyl-CoA synthetase (AMP-forming), and certain proteins of methanogenesis (Additional file 4).

\section{Proteins affected by multiple factors}

Several proteins were affected by two nutrient limitations (Table 4). A variety were negatively affected by $\mathrm{H}_{2}$-limitation and positively affected by nitrogen limitation. Others (proteins encoded in an operon involved in nickel transport and coenzyme $M$ biosynthesis) were negatively affected by $\mathrm{H}_{2}$-limitation and positively affected by phosphate limitation. AMP-forming acetylCoA synthetase was affected positively by nitrogen limitation and negatively by phosphate limitation. Flagellins were affected negatively by nitrogen limitation and positively by phosphate limitation. A study in Methanocaldococcus jannaschii observed a different effect, where $\mathrm{H}_{2}$ limitation resulted in an increase in flagella [18]. That study is not easily compared to the present one, since batch culture was used. However, it is possible that motility and chemotaxis in the two organisms have evolved to increase access to different vital nutrients. Another factor may lie in the ability of $M$. maripaludis but not $M$. jannaschii to fix nitrogen. Nitrogen fixation is an energy-demanding process and M. maripaludis under nitrogen fixing conditions may decrease other energy-demanding processes such as motility in order to conserve energy.

\section{Conclusion}

From this study we have gained new insights into the response of $M$. maripaludis to nutrient limitations. $\mathrm{H}_{2}$ limitation affected the proteins of methanogenesis more widely than we had previously appreciated. Many proteins of methanogenesis increased in abundance, in an apparent regulatory response to maintain flux through the methanogenic pathway when $\mathrm{H}_{2}$ is limiting. In contrast, the $\mathrm{H}_{2}$-dependent methylenetetrahydromethanopterin dehydrogenase $(\mathrm{Hmd})$ decreased. Under $\mathrm{H}_{2}$-limitation the function of Hmd may be replaced with the $\mathrm{F}_{420^{-}}$ 
Table 4: Selected proteins with abundance affected by more than one nutrient limitation.

\begin{tabular}{|c|c|c|c|c|}
\hline ORF \# & Function & Average $\log _{2}$ ratios $^{a}$ & & \\
\hline & & $\mathrm{H}_{2}$ limitation & Nitrogen limitation & Phosphate limitation \\
\hline MMPOI 27 & $\mathrm{Hmd}$ & -2.08 & 0.68 & \\
\hline MMPOI 25 & Hypothetical protein & -1.19 & 0.13 & \\
\hline MMP0875 & S-layer protein & -1.25 & 0.76 & \\
\hline MMPII76 & Putative iron transporter subunit & -0.83 & 0.63 & \\
\hline MMP0I64 & CbiX, cobaltochelatase & -0.59 & 0.31 & \\
\hline MMP027I & putative nickel transporter & -0.89 & & 0.70 \\
\hline MMP0272 & putative nickel transporter & -0.46 & & 0.84 \\
\hline MMP0273 & ComA, coenzyme $M$ biosynthesis & -0.58 & & 0.73 \\
\hline MMPOI48 & acetyICoA synthase, AMP-forming & & 0.23 & -0.98 \\
\hline MMPI666 & FlaBI, flagellin precursor & & -1.13 & 0.46 \\
\hline MMPI668 & FlaB3, flagellin & & -1.04 & 0.46 \\
\hline
\end{tabular}

aEach average $\log _{2}$ ratio is derived as described in Tables I, 2, and 3, and is from the ratios of the nutrient in question with the non-affecting nutrient limitation.

dependent methylenetetrahydromethanopterin dehydrogenase (Mtd) together with $\mathrm{F}_{420}$-reducing hydrogenase (Frc or Fru).

Many proteins that increased with nitrogen limitation have known functions in nitrogen assimilation and have similarly regulated counterparts in Bacteria and other Archaea $[19,20]$. Other proteins that increased apparently function in nitrogenase FeMoCo synthesis or to import molybdate for FeMoCo, or to import alanine when used as a nitrogen source. The results help to identify the regulon that is directly regulated by the nitrogen repressor NrpR.

The response to phosphate limitation supports the hypothesis that $M$. maripaludis has three alternative phosphate transporters, all of which increased under phosphate limitation.

\section{Methods}

\section{Culture conditions}

Methanococcus maripaludis strain Mm900 [11] was grown in chemostats as described [9], with the following modifications. Amino acid stocks were omitted from the medium, resulting in a defined medium that contained acetate, vitamins, and cysteine as the sole organic constituents. $\mathrm{NH}_{4} \mathrm{Cl}$ was added to the medium after autoclaving from a sterile anaerobic stock. Ar replaced $\mathrm{N}_{2}$ in the gas mixture. For growth of nitrogen-limited cultures, $\mathrm{NH}_{4}{ }^{+}$ was decreased to $3 \mathrm{mM}$ in the medium that was pumped into the chemostats, and for growth of phosphate-limited cultures, $\mathrm{PO}_{4}{ }^{2-}$ was decreased to $0.15 \mathrm{mM}$ (for sample 31) or $0.13 \mathrm{mM}$ (for sample 82 ). For growth of $\mathrm{H}_{2}$-limited cultures, $\mathrm{H}_{2}$ was decreased to $20 \mathrm{ml} / \mathrm{min}$ and the difference made up with Ar. The dilution rate in every case was 0.083 $\mathrm{h}^{-1}$, and the $\mathrm{OD}_{660}$ at harvesting was between 0.62 and 0.71 . Two cultures were obtained for each nutrient limitation, one grown with ${ }^{14} \mathrm{NH}_{4}+$ (natural abundance) and the other with ${ }^{15} \mathrm{NH}_{4}{ }^{+}$supplied as ${ }^{15} \mathrm{NH}_{4} \mathrm{Cl}$. Sample col- lection from the chemostats for proteomics was as described [5].

\section{Proteomics}

Proteomic analyses were conducted as described [8], with the primary exception that a Thermo LTQ linear ion trap mass spectrometer (Thermo-Fisher, San Jose, CA) has since replaced the LCQ Classic mass spectrometer for all work reported here. Details of the proteome extraction, trypsin digestion, solution volumes, off-line HPLC fractionation and 2-D capillary HPLC/tandem mass spectrometry, AKA MudPIT [21], Sequest database searching [22], DTASelect 1.9 in silico mapping of peptides to $M$. maripaludis protein-encoding ORFs [23], software and database release dates and versions were as described. Briefly, protein was extracted from each of the six cultures depicted in Figure 1. The six protein extracts were digested with trypsin and then combined pair wise as shown in Figure 1 , such that equal amounts of heavy $\left({ }^{15} \mathrm{~N}\right)$ and light $\left({ }^{14} \mathrm{~N}\right)$ total protein were used for each condition being compared, as determined by Bradford assay [24,25]. Each of the six combined heavy/light proteolysates shown in Figure 1 were pre-fractionated and analyzed twice by 2-D capillary HPLC/tandem mass spectrometry. The data from the two technical replicates were pooled, yielding a single dataset for each heavy/light mixture. These mass spectrometry datasets (see Additional data files) were labeled in the Hackett Lab archive as AH30-31-104 ( ${ }^{14} \mathrm{~N}$ phosphate, ${ }^{15} \mathrm{~N}$ ammonia), AH30-31-49 ( ${ }^{14} \mathrm{~N}$ phosphate, ${ }^{15} \mathrm{~N}$ hydrogen), AH30-49-98 ( ${ }^{15} \mathrm{~N}$ hydrogen, ${ }^{14} \mathrm{~N}$ ammonia), AH30-54-104 ( ${ }^{14} \mathrm{~N}$ hydrogen, ${ }^{15} \mathrm{~N}$ ammonia) AH30-82$54\left({ }^{15} \mathrm{~N}\right.$ phosphate, ${ }^{14} \mathrm{~N}$ hydrogen) and AH30-82-98 $\left({ }^{15} \mathrm{~N}\right.$ phosphate, ${ }^{14} \mathrm{~N}$ ammonia). To ensure that equimolar amounts of total protein were being compared, the Bradford assay results were confirmed by inspecting the calculated abundance ratio frequency distribution histograms for zero centering ( $\log _{2}$ scale) and making slight adjustments in the ratios where necessary [8]. In no case did the normalization of the ratios exceed a $5 \%$ change in the 
total signal observed in either channel $\left({ }^{14} \mathrm{~N}\right.$ or $\left.{ }^{15} \mathrm{~N}\right)$. Raw data from the six heavy/light mixtures (Figure 1) were processed as described previously, except as noted below, to yield abundance ratios reported in Additional file 1. Figure 2 illustrates the use of the abundance ratios derived from the six unique mixtures (Figure 1) of isotopic flips to calculate the total of 12 two-condition comparisons with four abundance ratios for each of the three limiting nutrient conditions, as reported in Additional files 2, 3, 4 for proteins showing significant abundance change. Statistical analysis differed from that reported previously [8] in that a $q$-value $[26,27]$ cut-off of 0.01 was used for all significance testing for abundance change between paired conditions, rather than $p$-values. The $q$-value is based on the concept of FDR (false discovery rate) and contains an explicit correction for multiple hypothesis testing that is lacking in an uncorrected $p$-value calculation [26]. At the level of qualitative peptide identifications, the estimated FDRs for the work reported here were $3 \%$, based on matches with reversed protein sequences in the decoy portion of the database $[28,29]$. Along with a minimum requirement of three unique peptide sequences required for each identification, this estimate suggests a low number of false positive protein level identifications. The composition, release dates, and other details of the FASTA database were the same as those reported previously [8], with the exception that the database has been approximately doubled in size to 40 Mbytes by addition of reversed sequences to the forward protein sequences for M. maripaludis (Genbank ${ }^{\mathrm{TM}}$ Accession BX950229) and addition of about $25 \%$ of the human subset of the nrdb [30]. For purposes of validating protein derived abundance ratios, qRT-PCR was conducted as described [8].

\section{Alanine transporter-lacZ fusion}

The promoter of the $\mathrm{Na}^{+}$-alanine symporter (MMP1511) gene was PCR-amplified from M. maripaludis S2 [31] genomic DNA using primers 5'AAACTAGTAATCAAGTATTTAAATCCGTTAC3' (forward) and $5^{\prime}$ ACCATGCATCCACTCCAAATTTTTTTGG (reverse). Herculase ${ }^{\circledast}$ (Stratagene) was used and conditions were $94^{\circ} \mathrm{C}$ for $2 \mathrm{~min} ; 30$ cycles of $94^{\circ} \mathrm{C}$ for $30 \mathrm{sec}$, $51^{\circ} \mathrm{C}$ for $30 \mathrm{sec}$, and $68^{\circ} \mathrm{C}$ for $30 \mathrm{sec}$; and a final extension of $68^{\circ} \mathrm{C}$ for $10 \mathrm{~min}$. Product was digested with SpeI and NsiI and cloned into pWLG40+lacZ to yield pWLG40agcsB2-1. Plasmid DNA was transformed [32] into Mm900 to give Mm1086. Growth of Mm1086 and $\beta$ galactosidase assay were as described [14]. Measurements were taken from triplicate cultures.

\section{Abbreviations}

2-D: two dimensional; Amt: ammonia transporter; $\mathrm{F}_{420}$ : coenzyme $\mathrm{F}_{420}$; FDR: false discovery rate; FeMoCo: ironmolybdenum cofactor; Fru: $\mathrm{F}_{420}$-reducing hydrogenase (selenocysteine-containing); GlnA: glutamine synthetase; GlnK: nitrogen sensor/regulator; $\mathrm{H}: \mathrm{H}_{2}$-limited; $\mathrm{Hmd}$ : $\mathrm{H}_{2}-$ dependent methylenetetrahydromethanopterin dehydrogenase; HPLC: high performance liquid chromatography; Mer: methylenetetrahydromethanopterin reductase; Mtd: methylenetetrahydromethanopterin dehydrogenase $\left(\mathrm{F}_{420}\right.$-dependent $) ; \mathrm{N}$ : nitrogen-limited; Nif: nitrogen fixation; NrpR: nitrogen regulatory protein; P: phosphate-limited; qRT-PCR: quantitative real-time reverse transcription-PCR.

\section{Authors' contributions}

QX and TW performed protein biochemistry, 2-D capillary HPLC separations, mass spectrometry and data analysis. ELH performed data analysis and bioinformatics. TJL assayed expression of the $\mathrm{Na}^{+}$-alanine symporter gene. $\mathrm{MH}$ and JAL supervised the research. JAL wrote the manuscript.

\section{Additional material}

\section{Additional file 1}

Complete list of protein abundance ratios, $\mathrm{p}$-values, and $\mathrm{q}$-values. Complete data set, with $\log _{2}$ ratios, $\mathrm{p}$-values, $\mathrm{q}$-values, and abundance trends (up, down, or no significant difference).

Click here for file

[http://www.biomedcentral.com/content/supplementary/14712180-9-149-S1.xls]

\section{Additional file 2}

Proteins with altered abundance under $\mathrm{H}_{2}$ limitation. $\log _{2}$ ratios for proteins with altered abundance under $\mathrm{H}_{2}$ limitation.

Click here for file

[http://www.biomedcentral.com/content/supplementary/14712180-9-149-S2.xls]

\section{Additional file 3}

Proteins with altered abundance under nitrogen limitation. $\log _{2}$ ratios for proteins with altered abundance under nitrogen limitation. Click here for file

[http://www.biomedcentral.com/content/supplementary/14712180-9-149-S3.xls]

\section{Additional file 4}

Proteins with altered abundance under phosphate limitation. Log2 ratios for proteins with altered abundance under phosphate limitation. Summary tables of individual proteomic results at the peptide level, in the form of DTASelect Ver. 1.9 filter files [23], are posted at http:// depts.washington.edu/mhlab/Mm900nutrientlimitation. Log in with user name MMP and password threebugs. These files are organized by the archive names given under Materials and Methods and contain Sequest [22] scores for individual peptide mass spectra, search parameters and other detailed information that can be used to assess data quality at multiple levels, i.e. peptides, proteins and individual CID $\left(\mathrm{MS}^{2}\right)$ mass spectra. The sequest.params file for each analysis is also posted. Researchers interested in the raw data ( ${ }^{*}$.RAW files) should contact mhackett@u.washington.edu.

Click here for file

[http://www.biomedcentral.com/content/supplementary/14712180-9-149-S4.xls] 


\section{Acknowledgements}

We thank Andrew Haydock for operation and maintenance of the chemostats, Brian Moore for qRT-PCR analyses, and Fred Taub for computer and bioinformatics support. This work was supported by the U.S. Department of Energy Office of Basic Energy Sciences, Basic Research for the Hydrogen Fuel Initiative, Grant No. DE-FG02-05ERI 5709; the Office of Science (BER), U.S. Department of Energy, Grant No. DE-FG02-08ER64685; and the National Institute of General Medical Sciences, Grant Nos. R24 GM074783 and ROI GM55255.

\section{References}

I. Thauer RK, Kaster AK, Seedorf H, Buckel W, Hedderich R: Methanogenic archaea: ecologically relevant differences in energy conservation. Nat Rev Microbiol 2008, 6(8):579-59l.

2. Lie TJ, Dodsworth JA, Nickle DC, Leigh JA: Diverse homologues of the archaeal repressor NrpR function similarly in nitrogen regulation. FEMS Microbiol Lett 2007, 27 I(2):28I-288.

3. Lie TJ, Leigh JA: A novel repressor of nif and glnA expression in the methanogenic archaeon Methanococcus maripaludis. Mol Microbiol 2003, 47(I):235-246.

4. Lie TJ, Wood GE, Leigh JA: Regulation of nif expression in Methanococcus maripaludis : roles of the euryarchaeal repressor NrpR, 2-oxoglutarate, and two operators. J Biol Chem 2005, 280(7):5236-524l.

5. Hendrickson EL, Haydock AK, Moore BC, Whitman WB, Leigh JA: Functionally distinct genes regulated by hydrogen limitation and growth rate in methanogenic Archaea. Proc Natl Acad Sci USA 2007, I 04(2I):8930-8934.

6. Hendrickson EL, Liu Y, Rosas-Sandoval G, Porat I, Söll D, Whitman WB, Leigh JA: Global responses of Methanococcus maripaludis to specific nutrient limitations and growth rate. I Bacteriol 2008, I 90(6):2198-2205.

7. Porat I, Kim W, Hendrickson EL, Xia Q, Zhang Y, Wang T, Taub F, Moore BC, Anderson IJ, Hackett M, et al:: Disruption of the operon encoding Ehb hydrogenase limits anabolic $\mathrm{CO}_{2}$ assimilation in the archaeon Methanococcus maripaludis. J Bacteriol 2006, I 88(4): | 373-1380.

8. Xia Q, Hendrickson EL, Zhang Y, Wang T, Taub F, Moore BC, Porat I, Whitman WB, Hackett M, Leigh JA: Quantitative proteomics of the archaeon Methanococcus maripaludis validated by microarray analysis and real time PCR. Mol Cell Proteomics 2006, 5(5):868-88I.

9. Haydock AK, Porat I, Whitman WB, Leigh JA: Continuous culture of Methanococcus maripaludis under defined nutrient conditions. FEMS Microbiol Lett 2004, 238(I):85-91.

10. Xia Q, Hendrickson EL, Wang T, Lamont RJ, Leigh JA, Hackett M: Protein abundance ratios for global studies of prokaryotes. Proteomics 2007, 7:2904-2919.

I I. Moore BC, Leigh JA: Markerless mutagenesis in Methanococcus maripaludis demonstrates roles for alanine dehydrogenase, alanine racemase, and alanine permease. J Bacteriol 2005 I 87(3):972-979.

12. Thauer RK, Klein AR, Hartmann GC: Reactions with molecular hydrogen in microorganisms: evidence for a purely organic hydrogenation catalyst. Chem Rev 1996, 96(7):303 I-3042.

13. Shima S, Pilak O, Vogt S, Schick M, Stagni MS, Meyer-Klaucke W, Warkentin E, Thauer RK, Ermler U: The crystal structure of [Fe]hydrogenase reveals the geometry of the active site. Science 2008, 32 I(5888):572-575.

14. Lie TJ, Leigh JA: Regulatory response of Methanococcus maripaludis to alanine, an intermediate nitrogen source. J Bacteriol 2002, I 84( I 9):530I-5306.

15. Cohen-Kupiec R, Blank C, Leigh JA: Transcriptional regulation in Archaea: in vivo demonstration of a repressor binding site in a methanogen. Proc Natl Acad Sci USA 1997, 94(4): I316-I320.

16. Cohen-Kupiec R, Marx CJ, Leigh JA: Function and regulation of glnA in the methanogenic archaeon Methanococcus maripaludis. J Bacteriol I999, I 8 I (I):256-26I.

17. Lamarche MG, Wanner BL, Crepin S, Harel J: The phosphate regulon and bacterial virulence: a regulatory network connecting phosphate homeostasis and pathogenesis. FEMS Microbiol Rev 2008, 32(3):461-473.

18. Mukhopadhyay B, Johnson EF, Wolfe RS: A novel $\mathbf{p H}_{2}$ control on the expression of flagella in the hyperthermophilic strictly hydrogenotrophic methanarchaeaon Methanococcus jannaschii. Proc Natl Acad Sci USA 2000, 97: I I 522-I I 527.

19. Leigh JA, Dodsworth JA: Nitrogen regulation in bacteria and archaea. Annu Rev Microbiol 2007, 6 I:349-377.

20. Veit K, Ehlers C, Ehrenreich A, Salmon K, Hovey R, Gunsalus RP, Deppenmeier U, Schmitz RA: Global transcriptional analysis of Methanosarcina mazei strain Gol under different nitrogen availabilities. Mol Genet Genomics 2006, 276(I):4I-55.

21. Washburn MP, Ulaszek R, Deciu C, Schieltz DM, Yates JR 3rd: Analysis of quantitative proteomic data generated via multidimensional protein identification technology. Anal Chem 2002, 74: $1650-1657$.

22. Eng JK, McCormack AL, Yates JR 3rd: An approach to correlate tandem mass-spectral data of peptides with amino-acidsequences in a protein database. J Am Soc Mass Spectrum 1994, 5:976-989.

23. Tabb DL, McDonald WH, Yates JR 3rd: DTASelect and Contrast: tools for assembling and comparing protein identifications from shotgun proteomics. J Proteome Res 2002, I:2I-26.

24. Bradford MM: A Rapid and Sensitive Method for the Quantitation of Microgram Quantities of Protein Utilizing the Principle of Protein-Dye Binding. Anal Biochem 1976, 72:248-254.

25. Zor T, Selinger Z: Linearization of the Bradford protein assay increases its sensitivity: theoretical and experimental studies. Anal Biochem 1996, 236:302-308.

26. Storey JD, Tibshirani R: Statistical significance for genome wide studies. Proc Natl Acad Sci USA 2003, I 00:9440-9445.

27. Xia Q, Wang T, Park Y, Lamont RJ, Hackett M: Differential quantitative proteomics of Porphyromonas gingivalis by linear ion trap mass spectrometry: Non-label methods comparison, qvalues and LOWESS curve fitting. Int J Mass Spectrom 2007, 259: $105-116$.

28. Peng J, Elias JE, Thoreen CC, Licklider LJ, Gygi SP: Evaluation of multidimensional chromatography coupled with tandem mass spectrometry (LC/LC-MS/MS) for large-scale protein analysis: the yeast proteome. J Proteome Res 2003, 2:43-50.

29. Elias JE, Gibbons FD, King OD, Roth FP, Gygi SP: Intensity-based protein identification by machine learning from a library of tandem mass spectra. Nat Biotechnol 2004, 22:214-219.

30. human.protein.faa [http://www.ncbi.nlm.nih.gov/Ftp/]

31. Hendrickson EL, Kaul R, Zhou Y, Bovee D, Chapman P, Chung J, Conway de Macario E, Dodsworth JA, Gillett W, Graham DE, et al.: Complete genome sequence of the genetically tractable hydrogenotrophic methanogen Methanococcus maripaludis. J Bacteriol 2004, 186:6956-6969.

32. Tumbula DL, Makula RA, Whitman WB: Transformation of Methanococcus maripaludis and identification of a Pst I-like restriction system. FEMS Microbiol Lett 1994, I 2 1:309-3 I4.

\section{Publish with Biomed Central and every scientist can read your work free of charge}

"BioMed Central will be the most significant development for disseminating the results of biomedical research in our lifetime. "

Sir Paul Nurse, Cancer Research UK

Your research papers will be:

- available free of charge to the entire biomedical community

- peer reviewed and published immediately upon acceptance

- cited in PubMed and archived on PubMed Central

- yours - you keep the copyright
BioMedcentral 